Odette ARHIP, Universitatea Ecologică București

Cristian ARHIP, Universitatea de Medicina și Farmacie „Gr. T. Popa”, Iași

\title{
DEVALORIZAREA SEMANTICĂ A CUVINTELOR INN PUBLICITATEA SPORTIVĂ
}

Viața modernă implică noi ritualuri.

„Ritul se înscrie în viața socială prin refacerea circumstanțelor care determină repetarea efectuării lui. Ritul nu se mărginește la fenomenul religios"[1].

Unul dintre aceste rituri e sportul, producător de eroi care nu mai au un destin mesianic, dar dețin măcar o calitate excepțională. Pentru aceasta, se utilizează cuvinte, de obicei, cu numeroase conotații substanţiale, importante, însă bogăția semantică alunecă în derizoriu din cauza contextului simplu ori ridicol deoarece opinia unor creatori de publicitatea se întemeiază pe un principiu greșit: o reputație, valoarea, prestigiul unui erou/model (exemplele, din prezentul text, sunt din lumea sportului) vinde un produs și nu afectează vocabularul. Ambele premise sunt false și una dintre acestea afectează și lexicul limbii române.

Goana după imagine este, din păcate, o caracteristică a epocii în care trăim. Ambalajul prevalează în raport cu expresia verbală. Se poate afirma, fără un risc major de a greși, că societatea contemporană e din nou pradă ușoară pentru forma fără fond. Cuvântul este utilizat rar atât în dialogurile obișnuite, cât și în alte manifestări ale comunicării. Și nu facem referire la clasica complementaritate cu paraverbalul și nonverbalul. Oamenii de azi, generațiile tinere și cele de vârstă mijlocie, preferă semnul vizual, chiar dacă acesta este doar aparent mai ușor de descifrat. Faptul că nu se vede ușor tot ce trebuie să se vadă și să se înțeleagă reprezintă tema multor volume, articole, contribuții diverse.

Acolo unde vizualul e greu de sensuri se creează o zonă de tensiune, uneori chiar de frustrare, între ceea ce se arată și ceea ce trebuie să caute privitorul. Totodată, din perspectiva limbii, a celor care o vorbesc, se constată o evidentă sărăcire. „Privilegiul clarității dispare"[2]. Dispare și bogăția semantică în reclamele care subevaluează, nu cunosc, ori ignoră puterea întreagă a semnului verbal. Subtilitatea solicită transpunerea privitorului, un efort de interpretare și nu puțini sunt cei care regretă că nu mai găsesc sprijinul cuvântului. Imaginea poate fi o frântură de oglindă a realității în mesajele simpliste, banale, strict transmițătoare de informație. Imaginea constituie un element important al reclamei, dar nu autosuficient. 
Dintotdeauna reclama a avut nevoie de eroi. Cei non-ficționali sunt mai convingători și publicitatea se orientează des spre lumea sportului. Sportivii sunt cunoscuți, respectați, constituie adevărate modele sau devin idoli. De aceea, publicul țintă al oricărui produs tinde să copie comportamentul fără a acorda multă atenție produsului ori serviciului achiziționat. În consecință, cum să nu se rețină că s-a deschis un Selgros în Târgu Mureș dacă vezi un spot în care însuși Hagi ia taxiul pentru a fi prezent la eveniment? În mod clar, „eroismul nu dispare, ci este hrănit de nevoia omului de a rezolva diferite probleme imediate."[3]. Din punct de vedere lingvistic însă, dialogul dintre Hagi și șoferul de taxi cu un accent ardelean, care accentuează locaţia, e foarte sărac, înscris în limitele colecvialității.

Iată o statistică a sportivilor români considerați branduri care pot vinde produse, servicii, evenimente, proiecte, invenții, iniţiative civice etc. A se urmări, în paralel, și criteriile:

\section{Notorietate}

1. Simona Halep $99 \%$

2. Cătălina Ponor $96 \%$

3. Horia Tecău $87 \%$

4. Cătălin Moroșanu 86\%

5. Ana Maria Brânză $82 \%$

6. Cristina Neagu $73 \%$

7. Alex Chipciu 72\%

8. Denisa Dedu 50\%

9. Ion Oncescu $46 \%$

10. Corina Căprioriu 37\%

\section{Appeal}

1. Cătălina Ponor $77 \%$

2. Cristina Neagu $77 \%$

3. Ticu Lăcătușu $71 \%$

4. Simona Halep 70\%

5. Ana Maria Brânză 70\%

6. Horia Tecău $69 \%$

7. Denisa Dedu 68\%

8. Elizabeta Samara $66 \%$

9. Robert Glință 65\%

10. Andrei Roșu $64 \%$ 


\section{Do-er roman}

1. Cătălina Ponor $82 \%$

2. Cristina Neagu $81 \%$

3. Simona Halep 77\%

4. Horia Tecău 75\%

5. Ana Maria Brânză 75\%

6. Andrei Roșu 73\%

7. Ticu Lăcătușu 71\%

8. Denisa Dedu 69\%

9. Elizabeta Samara 68\%

Model, exemplu

1. Cătălina Ponor 11

2. Simona Halep 11

3. Cristina Neagu 11

4. Horia Tecău 10

5. Ana Maria Brânză 8

6. Ticu Lăcătușu

Index sportive

1. Cătălina Ponor

2. Simona Halep

3. Cristina Neagu

4. Horia Tecău

5. Ana Maria Brânză

Asociere cu energia

1. Ticu Lăcătușu $82 \%$

2. Cristina Neagu $80 \%$

3. Andrei Roșu 77\%

4. Robert Glință 75\%

5. Valentin Calafeteanu 75\%

Asociere cu brandul

1. Simona Halep $12 \%$

2. Ticu Lăcătușu $12 \%$

3. Valentin Porcișteanu 9\%

4. Cătălin Moroșanu 9\%

5. Cristina Neagu 8\%

6. Horia Tecău 8\% 


\section{Index potrivire cu brandul Amigo}

\section{Cătălina Ponor}

2. Cristina Neagu

3. Simona Halep

4. Ana Maria Brânză

5. Horia Tecău

Să examinăm câteva reclame în care eroii tradiționali sunt înlocuiți de celebrități din lumea sportului selectați conform criteriilor anterioare. În toate mesajul suferă de un caracter succinct, sărac în conotații ori subtilități de la început pentru că se apreciază că eroul/model și o schiță de context sunt suficiente pentru atingerea obiectivelor.

Simona Halep, nr. 1 mondial în tenisul feminin, figurează în numeroase spoturi dintre cele care ating pragul de jos al creativității, sărăcind concomitant lexicul românesc din punct de vedere semantic. Sportiva apare, de exemplu, în reclamele Dedeman (cu sloganul Dedicat planurilor tale) ca simplă eroină de succes, necreându-se nicio legătură logică, semantică ori metaforică între ea și produsul vândut. Obiectul comercializat este doar un alt component al echipei în care Simona e căpitanul: email cu uscare rapidă, materiale pentru tencuială, vopsea, canapea etc. Se poate constata, în aceste tentative publicitare, o lipsă de profesionalism pentru că nu se poate vinde o sumedenie de articole numai cu sloganul Lasă-i să bată mingea! ce sugerează doar o regresie către vârsta copilăriei în timpul căreia fiecare om e fericit și are impresia că visurile lui vor deveni realitate, permisivitatea armonizându-se cu indulgența. Este prea simplist, neprelucrat, lipsit de imaginație, chiar dacă autorii își pot motiva pasivitatea prin calitatea de sponsori ai sportivei ori prin convingerea că o vedetă vinde și transmite mesajul oricum. În prezentul demers se comentează calitatea produsului publicitar.

Astfel, într-unul dintre spoturile Dedeman, performanța Simonei Halep este salutată cu interjecția Bravo!, rămânându-se la un nivel de comunicare globală, generală, în care un erou, în sensul modern al termenului, este folosit numai pentru a atinge obiectivele comerciale, fiind doar un mijloc de a influența consumatorii. Observația noastră coincide cu ce se știe deja din multele cărți consacrate publicității:

„Nivelul acesta de influență indică, de fapt, gradul de eroism din contemporaneitate, măsurat în rating, popularitate și alți factori de creștere a audienței. Este mare saltul de la curaj, jertifirea propriei libertăți sau a vieții până la o simplă apariție în public pe care masele s-o agreeze și s-o urmeze."[4]. 
Cuvântul își pierde încărcătura semantică, nu mai este echivalentul excelenței prin el însuși, adică un echivalent al gradului superlativ, ci un simplu instrument de provocare a interlocutorului (funcție retorică/conativă).

În opinia noastră, este o situație care poziționează astfel de mesaje în antiteză cu textul gnomic (proverbele). Ultimul

„se întemeiază pe principiul metaforic, înțeles ca transcendere a lumii fenomenale [...] și, în planul sintagmatic, enunțul ... îşi actualizează propriul plan semantic din perspectiva funcției specifice de comentariu în legătură cu lumea evenimențială"[5].

„Proverbul se impune ca un criteriu de interpretare a raportului dintre ființa umană și lume ... și își relevă esența sa sapiențială" [6].

Cuvintele, ce compun mesajele din spoturi, utilizează prea mult sensul denominativ şi se bazează pe semnificația inculcată memoriei colective, nedezvoltându-se dimensiunile cognitive și etice ale comunicării așa cum ar fi normal.

Vodafone își promovează unul dintre servicii (Supernet 4G) tot prin intermediul Simonei Halep, dar la fel de anost - doar interjecția predicativă Hai nu poate soluționa sentimental de anxietate pe care îl resimt mulți subiecți care trăiesc acut „conflictul dintre Eul real și imaginea idealizată" [7]. Românii, ca orice alt popor, își susțin eroii sportivi, dar discrepanța financiară majoră și nivelul de trai tot mai scăzut fac ca produsele și serviciile Vodafone să fie inaccesibile pentru mulți. Astfel, spotul, în care sunt implicate bunicile (Bunici de duminică), face iar o trimitere explicită la vremurile copilăriei, dar aduce în prim-plan o categorie de vârstă care nu se suprapune peste publicul-țintă. Așa-zisa rivalitate dintre gospodine ar contamina-o pe Simona care participă și la turneul campioanelor în bucătărărie, dar totul este forțat. Normalul se rezumă la persoana ei, singura care are, de altfel, un mobil în mână sau la dispoziție sub pretextul filmării preparării plăcintei. Bunicile, care îl substituie pe fiecare român evocat în mesajul de la finalul spotului, nu au, nu știu și nu sunt publicul țintă al aplicației consacrate bucătăritului pe net. Mesajul este neconvingător, iar fondul musical (un remix al Fetelor de la Căpâlna) se resimte clar ca un corp străin în acest spot-improvizație, bazat doar pe renumele tenismenei. Articularea narativă lipsește cu desăvârşire. Adăugarea cuvintelor forehand, copil de mingi, turneul campioanelor pare a susține asocierea cu jucătoarea de tenis, dar îndemnul final Hai pe net la bunici să mâncăm împreună nu se construiește într-un îndemn convingător. Interjecția verbalizată Hai nu reușește să decanteze nicio dimensiune 
semantică afectivă, parodică ori ironică. Ne confruntăm cu un mare și banal malentendu. De pildă, credem că ar fi fost mult mai expresivă sugerarea unei antiteze între generația tânără consumatoare de tehnologie care se preocupă de rețețe mai vechi, bricolând culinar într-o duminică, și oamenii de vârsta a treia cu experiență, flexibili și dornici să învețe să utilizeze mobilul si aplicația în cauză.

Este adevărat că endorsement-ul are o dimensiune pozitivă deoarece recunoaște și susține performanța, succesul, celebritatea, valoarea, dar trebuie să existe armonie și potrivire. Rolul personajelelor trebuie să vină mănuşă pentru serviciul promovat. Pentru a adăuga un argument în sprijinul celor susținute facem o paralelă între spotul amintit și testimonialul în care apare Mihaela Rădulescu pentru uleiul Floriol. Nefiind vorba de bucătărie în sens traditional, à la bunici, ci de un stil de viață sănătos confirmat de silueta vedetei faptul că Mihaela pregătește o salată e veridic. Există compatibilitate.

„Mi-am schimbat dieta: mâncâns salate, brânzeturi, pește, iar Floriol mediteranean, o combinație unică de ulei de floarea-soarelui și măsline, este exact ce-mi trebuie..."[8].

Aplicația culinară Vodafone este greu de asociat cu stilul de viață rapid, dispunând de foarte puțin timp liber al Simonei, iar bunicile adjuvante nu sunt congruente cu domeniul sportului și cu cel al telefoniei mobile. Totuși, constatăm o situație tipică pentru genul de personaj aferent spoturilor publicitare. Când spotul are susținerea unui brand de personalitate, vedeta devine un construct stabil, asociabil cu orice context narativ „independent față de orice variabilă verbală, cu o existență fundamentată pe oricare alte elemente...Eroul își găsește locul oriunde în universal diegetic" [9], dar părerea enunțată de autorul citat nu ni se pare că se verifică chiar în orice context, mai ales atunci când diegeticul sfidează ridicolul.

Adăugăm un exemplu de aceeași factură, din păcate - spotul pentru Lotto Best Foods în care apare ca endorsement G. Hagi. Cuvântul legendă asociat cu adjectivul mare îşi pierde importanța semantică, iar celebrul fotbalist român este într-un mod neonorant asociat cu un produs alimentar minor, snack-uri. Termenii utilizați dragoste, cunoștințe, calitate implică principii morale și sentimentale atât de importante, încât trasmiterea acestora către generațiile următoare nu și-o poate nimeni imagina ca realizându-se prin analogia cu snack-urile. Includerea fiului lui Hagi, Ianis, în spot și-ar dori să sprijine mesajul inițial, dar nu reușește să minimalizeze ridicolul. Imaginea centrată pe punga cu snack-uri și auzirea cuvântului 
valoare subliniază flagranta discrepanță de importanță dintre endorsement și produsul promovat. Selectarea inspirată a termenilor de pe axa verticală a paradigmaticului, a vocabularului, se impune a fi dublată de o combinare la fel de expresivă a semnelor verbale și vizuale pe axa orizontală a sintagmaticului.

Şi mai nereuşită este varianta Lotto Peanuts. Mingea expediată de marele fotbalist este oprită magic şi se transformă într-un snack minuscul între degetele portarului. Puștiul din poartă devine un fel de erou-mag ce intervine, preferând snack-urile în detrimental idolului pe care ar trebui să îl venereze. Mesajul Lotto Peanuts înving până și legendele ar dori să fie tocmai subtitrarea la o astfel de vrajă făcută de copilul din poartă care oprește mingea șutată de Hagi și o preface în snack. Se dorește a reprezenta ceva neobișnuit, dar nu stimulează atenția consumatorului. Dimpotrivă. În funcție de vârstă și de pregătire, consumatorul zâmbește dezamăgit, râde de această tentativă comică de a promova un produs, anihilându-se orice interes sau dorință de a consuma produsul în cauză ori se complace în indiferență. Nu doar ridicola asociere reprezintă un minus al acestui spot. Acesta „deșteaptă atenția numai pentru foarte scurtă durată"[10]. Tocmai super-eroul (Hagi) ar trebui să fie cel înzestrat în reclame cu puteri supranaturale și capabil să rezolve în mod miraculos o problemă. Puterea lui se cuvine hiperbolizată, nu ridiculizată. Pentru a se înțelege mai bine acest aspect, facem trimitere la spotul în care Horia Brenciu zboară mai repede decât un avion pentru a personifica viteza internetului. Ce preferă orice consumator? Să vadă un gol marca Hagi ori să mănânce un snack? Oricât de amalgamată ar fi cultura consumatorului, răspunsul este evident. Eroul unei reclame corespunde arhetipului cuceritorului, salvatorului, generosului etc. şi el este "locomotiva din spatele atributelor personale valoroase"[11].

În încheiere, să oferim și un exemplu opus în care procesul comunicării are o plus-valoare. Toate aceste calități ale eroului și trăsături ale unei reclame sunt respectate în campanie promișcare a brandului Rexona, având-o ca protagonistă pe Simona Halep - Rexona te provoacă la 5000 de pași pe zi, Rexona nu te lasă la greu. Nici Halep nu te lasă la greu pentru că se străduiește să practice toate sporturile cu mare audiență și mesajul se dovedește pertinent: De fapt, important este să incerci. Măcar 5000 de paşi. Aflată la frontiera dintre marketing și comunicare creativă, publicitatea trebuie să încerce să vândă, să promoveze etc. într-un mod creativ. Ca într-un basm, eroina este supusă unor încercări (practicarea mai multor sporturi, excluzând tenisul) pentru care se găsesc rezolvări ludice și pline de entuziasm, verbalul susținând destul de consistent imaginea. 
Narațiunea este subiectivă, luând forma unei biografii televizate. Aici, Simona devine erou și pentru că se distinge prin iniţiativa de a încerca, iar spectatorii nu aderă doar la apelul filmat, ci și la cel verbal.

\section{NOTE:}

[1]. Bonte, P., Izard, M., Dicționar de etnologie și antropologie, Editura Polirom, Iași, 2007, p. 584.

[2]. Stoichiță, V. I. Vezi?, Editura Humanitas, București, 2007, p. 29.

[3]. Moraru, M., Poveștile publicitare de la inspirație la strategie, Editura Tritonic, București, 2015, p. 76.

[4]. Moraru, M., Poveștile publicitare de la inspirație la strategie, Editura Tritonic, București, 2015, p. 78.

[5]. Irimia, D., Introducere în stilistică, Editura Polirom, Iași, 1999, p. 133.

[6]. Irimia, D., Introducere în stilistică, Editura Polirom, Iași, 1999, p. 134.

[7]. Stoica-Constatin, A., Conflictul interpersonal, Editura Polirom, Iași, 2004, p. 91.

[8]. Moraru, M., Poveștile publicitare de la inspirație la strategie, Editura Tritonic, București, 2015, p. 84.

[9]. Margolin, U., Characters in Literary Narrative: Representation and Signification, in Semiotica no. 106, 1995, p. 375.

[10]. Todoran, D., Psihlogia reclamei, Editura Tritonic, București, 2005, p. 75.

[11]. Moraru, M., Poveștile publicitare de la inspirație la strategie, Editura Tritonic, București, 2015, p. 94.

\section{BIBLIOGRAFIE:}

Irimia, D., Introducere în stilistică, Editura Polirom, Iași, 1999.

Margolin, U., Characters in Literary Narrative: Representation and Signification, in Semiotica no. 106, 1995.

Moraru, M., Poveștile publicitare de la inspirație la strategie, Editura Tritonic, București, 2015.

Stoica-Constatin, A., Conflictul interpersonal, Editura Polirom, Iași, 2004.

Stoichiță, V. I., Vezi?, Editura Humanitas, București, 2007.

Todoran, D., Psihlogia reclamei, Editura Tritonic, București, 2005.

https:// www.youtube.com/watch? $\mathrm{v}=2014 x x$ xolgPU accesat pe 28. 10. 2018

https:// www.youtube.com/watch?v=YTSqA2jMGLA accesat pe 28. 10. 2018

https://www.youtube.com/watch?v=_FoQ1z7AREc accesat pe 28. 10. 2018

https://www.youtube.com/watch?v=Mi2snUyOkvs accesat pe 29.10. 2018

https:// www.youtube.com/watch?v=lokspY17gAU accesat pe 30.10. 2018 


\title{
Comments upon the Semantic Value of Words in Sport Advertising
}

\begin{abstract}
Sport is one of the rituals of modern life. It reunites appropriate words when engaging in advertising, but the number of terms is rather limited. The ads prefer to include the image of a sports personality and brand name. Since the advertising hero is notorious, the persuasive force is assured by few verbal arguments. Typically, the pictures speak for themselves, joining a musical background and some funny instances. Words, which normally send so much information, are subjected to a gradual semantic loss. Our paper intends to comment upon this worrying aspect of vocabulary dynamics, highlighting terms used in spots (i.e. myth, legend, team, success, value, passion, good, thrilling etc.) but whose significance goes unnoticed or is misunderstood by the public. Our purpose is to illustrate the crisis of language and communication. They do not decompose like in the case of absurd literature, but become platitudes for a segment of the audience either ignorant or illiterate.
\end{abstract}

Key words: vocabulary, meaningless, advertising, model, hero. 